\section{Students' and Teachers' Perceptions and Experiences of Classroom Assessment: A Case Study of a Public University in Afghanistan}

Sayed Ahmad Javid Mussawy, PhD Candidate

University of Massachusetts Amherst, Amherst, Massachusetts, United States

(iD https://orcid.org/oooo-00o1-9991-6681

Gretchen Rossman, $\mathrm{PhD}$

University of Massachusetts Amherst, Amherst, Massachusetts, United States

(iD) https://orcid.org/0000-0003-1224-4494

Sayed Abdul Qahar Haqiqat, MEd

Baghlan University, Pule-khumri, Baghlan, Afghanistan

Contact: smussawy@umass.edu

\section{Abstract}

Objective: The primary goal of the study was to examine students' perceptions of classroom assessment at a public university in Afghanistan. Exploring current assessment practices focused on student and faculty members lived experiences was a secondary goal. The study also sought to collect evidence on whether or not the new assessment policy was effective in student achievement.

Method: Authors used an explanatory sequential mixed-methods design to conduct the study. Initially, we applied the Students Perceptions of Assessment Questionnaire (SPAQ), translated into Dari/Farsi and validated, to collect data from a random sample of 400 students from three colleges: Agriculture, Education, and Humanities. Response rate was $88.25 \%(N=353)$. Semi-structured interviews were used to collect data from a purposeful sample of 18 students and 7 faculty members. Descriptive statistics, one-way ANOVA, and $t$-tests were used to analyze quantitative data, and NVivo 12 was used to conduct thematic analysis on qualitative data.

Results: The quantitative results suggest that students have positive perceptions of the current assessment practices. However, both students and faculty members were dissatisfied with the grading policy, reinforcing summative over formative assessment. Results support that the policy change regarding assessment has resulted in more students passing the courses compared to in the past. The findings also suggest improvements in faculty professional skills such as assessment and teaching and ways that they engage students in assessment processes.

Implication for Policy and Practice: Recommendations include revisiting the grading policy at the national level to allow faculty members to balance the formative and summative assessment and utilizing 
assessment benchmarks and rubrics to guide formative and summative assessment implementation in practice.

Keywords: assessment, classroom assessment, higher education, Afghanistan

Submitted: March 14, 2021 | Accepted: July 23, 2021 | Published: October 13, 2021

\section{Recommended Citation}

Mussawy, S. A. J., Rossman, G., \& Haqiqat, S. A. Q. (2021). Students' and teachers' perceptions and experiences of classroom assessment: A case study of a public university in Afghanistan. Higher Learning Research Communications, 11(2) 22-39. DOI: 10.18870/hlrc.v11i2.1244

\section{Introduction}

Classroom assessment, an instrumental aspect of teaching and learning, refers to a systematic process of obtaining information about learner progress, understanding, skills, and abilities towards the learning goals (Dhindsa et al., 2007; Goodrum et al., 2001; Klenowski \& Wyatt-Smith, 2012; Linn \& Miller, 2005). According to Scriven (1967) and Poskitt (2014), educational assessment surfaced in the 2oth century to serve two purposes. The first was to improve learning (formative assessment), and the second was to make judgments about student learning (summative assessment). The current literature on assessment emphasizes establishing alignment between educational expectations versus student learning needs (Black et al., 2003; Gulikers et al., 2006; Mussawy, 2009). Therefore, teachers use various forms of assessment to determine where students are and create diverse activities to help them achieve the expected outcomes (Mansell et al., 2020).

As most countries have expanded their higher education systems by embracing broader access to higher education, the student population has also become diverse (Altbach, 2007; Salmi, 2015). The more diverse student population suggests that conventional assessment approaches may no longer work. Therefore, alternative assessment approaches need to put students in the center to avoid wasting "learning for drilling students in the things that they [teachers] will be held accountable [for]” (Dhindsa et al., 2007, p. 1262).

The concept of classroom assessment has been loosely defined in the higher education sector of Afghanistan. While students and teachers are aware of different assessment approaches, current assessment practices rely heavily on conventional summative assessment (Mussawy, 2009; Noori et al., 2017). Previously, final exams were the only mechanisms to assess student learning (UNESCO-IIEP, 2004). However, higher education reform in Afghanistan in the early 2000 s paved the way for introducing mid-term exams and the credit system that replaced the conventional course structure based on the number of subjects (Babury \& Hayward, 2013; Hayward, 2017). More specifically, in the traditional system, the value of final grades for each subject was the same, irrespective of the number of hours the subject was taught per week. However, in the credit system, the value of grades varies depending on credit hours per week. Further, due to the absence of specific regulations on assessment approaches, faculty members enjoyed immense autonomy in assessing student learning. Since most of the faculty members had not received any training on pedagogy and assessment, they primarily relied on conventional open-ended summative assessment (Darmal, 2009).

In 2014, the Ministry of Higher Education (MoHE) in Afghanistan introduced a new assessment policy that centers on (a) transparency through the establishment of assessment committees at the institution and faculty levels and (b) the type and the number of question items in an exam (Ministry of Higher Education (MoHE), 2018). The second component, which is the focus of this study, indicates that assessment includes "evaluation of quizzes, mid-term exams, assignments, laboratory projects, class seminars and projects, final exams, and thesis and dissertations" (MoHE, 2018, p. 5). While mid-term and final exams constitute $20 \%$ and $60 \%$ of students' grades, respectively, the policy emphasizes "30-40 question items on final exams" and "a minimum of 10 items on mid-terms" (MoHE, 2018, p. 7). The policy also recommends a combination of closed-ended 
and open-ended questions with a value of " $3-5$ points" for descriptive and analytic items and " 1 point for multiple-choice questions” (MoHE, 2018, p. 5).

Although the assessment policy recognizes various approaches, such as quizzes, assignments, student projects, seminars, and mid-term and final exams, formative assessment and class attendance account for only $20 \%$ of a student's grade. Mid-term and final exams, on the contrary, constitute $80 \%$ of students' grades; this indirectly projects more value for summative over formative assessment. Therefore, perceptions of students and faculty members can shed light on current practices and participants' experiences of classroom assessment.

\section{Review of Literature}

The focus of classroom assessment has gradually shifted from assessment of learning-"testing learning" (Birenbaum \& Feldman, 1998, p. 92) to assessment for learning-creating diverse opportunities for learners to prosper (Brown, 2005; Wiliam, 2011). This is because research shows that classroom assessment significantly affects the approach students take to learning (Pellegrino \& Goldman, 2008). More specifically, new assessment approaches encourage an increase in correspondence between student learning needs and expectations to prosper in a changing environment (Gulikers et al., 2006). Goodrum et al. (2001) argued that, ideally, assessment "enhances learning, provides feedback about student progress, builds self-confidence and self-esteem, and develops skills in evaluation" (p. 2). Nonetheless, Dhindsa et al. (2007) stated that [primary and secondary school] teachers "sacrifice learning for drilling students in the things that they will be held accountable for" (p. 1262). This suggests that teachers use "a very narrow range of assessment strategies" to help students prepare for high-stakes tests, while limited evidence exists to support that "teachers actually use formative assessment to inform planning and teaching" (Goodrum et al., 2001, p. 2). Most importantly, recent research on classroom assessment emphasizes the quality and relevance of assessment activities to help students learn (Ibarra-Saiz et al., 2020).

Inquiring into students' perception of assessment has been an important aspect of the literature on classroom assessment (Koul et al., 2006; Segers et al., 2006; Struyven et al., 2005; Waldrip et al., 2009). Examining their perceptions confirms the assumption that assessment "rewards genuine effort and in-depth learning rather than measuring luck" (Dhindsa et al., 2007, p. 1262). For this reason, recent studies on classroom assessment advocate for student involvement in developing assessment tools (Falchikove, 2004; Waldrip et al., 2014) to make the learning process more valuable to students. With this in mind, Fisher et al. (2005) developed Students Perceptions of Assessment Questionnaire (SPAQ) and confirmed its validity by applying it to a sample consisting of 1,000 participants from 40 science classes in grades $8-10$. Following that, Cavanagh et al. (2005) modified and adapted the SPAQ as an analytic tool to study student perceptions of classroom assessment in five specific areas: Congruence with planned learning (CPL), assessment of applied learning (AAL), students' consultation (SC) types, transparency in assessment (TA), and accommodation of students' diversity (ASD) in assessment procedures. Cavanagh et al. (2005) used SPAQ to study 8th through 1oth grade student perceptions of assessment in Australian science classrooms. Their study showed that student perceptions of assessment in science subjects varied depending on their abilities.

Other studies examining students' perceptions of assessment reveal diverse responses. For instance, Koul et al. (2006) modified, validated, and applied SPAQ on a 4-point Likert scale to study secondary student perceptions of assessment in Australia. Their study shows that the difference between males' and females' perceptions of assessment was not statistically significant. However, they reported statistically significant differences in student perceptions of assessment by grade level. Similarly, Dhindsa et al. (2007) used SPAQ to examine high school student perceptions of assessment in Brunei Darussalam and learned that the Student Consultation was rated the lowest of the scales. Their findings suggest that students perceived assessment as 
transparent and as aligned with learning goals. However, they did find that teachers hardly consulted with students regarding assessment forms.

Kwok (2008) also studied student assumptions of peer assessment and reported that, while students perceived peer assessment as substantially important in enhancing self-efficacy, they considered themselves unprepared relative to their teachers who brought years of experience. In another study, Segers et al. (2006) examined college students' understanding of assignment-based learning versus problem-based learning. Their study showed that students in the assignment-based learning course embraced "more deep learning strategies and less surface-learning strategies than the students in the PBL [problem-based learning] course" (Segers et al., 2006, p. 234). They reported that students in the PBL course showed surface-level learning strategies (Segers et al., 2006, p. 236). Although the context varied, their findings are partly consistent with those of Birenbaum and Feldman (1998), who examined 8th through 1oth-grade student attitudes towards openended versus closed-ended response assessment. They reported that gender and learning strategies were significantly correlated in that female students leaned towards essay questions while male students favored closed responses. In other words, students who demonstrated the "surface study approach" preferred closeended question items as opposed to those with "deep study approach," favoring open-ended questions (Birenbaum \& Feldman, 1998).

However, Beller and Gafni's (2000) study shows that although boys favored multiple-choice questions items in mathematics assessment, the difference between performance based on gender was not profound. Their study focused on the relationship between question format, examining whether multiple choice versus openended questions accounted for gender differences. Their study "results challenge the simplistic assertion that girls perform relatively better on OE [open-ended] test items" (Beller \& Gafni, 2000, p. 16). On a similar note, Van de Watering et al. (2008) found no "relationship between students' perceptions of assessment and their assessment results" (p. 657). They reported that students prefer close-ended question formatting when attending to a "New Learning Environment" (Van de Watering et al., 2008, p. 245).

Meanwhile, Struyven et al. (2005) studied the relationship between student perceptions of assessment and their learning approaches. In general, students preferred close-ended questions; however, students with advanced learning abilities and with low test anxiety favored essay exams. Lastly, Ounis (2017) investigated perceptions of classroom assessment among secondary school teachers in Tunisia. The author reported that the teachers "have highly favorable perceptions of assessment and they hold highly the motivational function of assessment" (p. 123). According to Ounis (2017), the teachers emphasized oral assessment as a useful approach to increase learning even though they reported some challenges to implementing the oral assessment.

Although assessment in higher education is loosely defined relative to assessment at the primary and secondary education levels, recent literature sheds light on introducing alternative/formative assessment tasks such as portfolios, applied research projects, and others (Bess, 1977; Ibarra-Sáiz et al., 2020; Nicol \& Macfarlane-Dick, 2006; Struyven et al., 2005). Further, to date, research on perceptions and experiences of undergraduate students and faculty members in Afghanistan is scarce. For instance, Noori et al. (2017) and Darmal (2009) studied assessment practices of university lecturers in Afghanistan. However, the scope of these research studies is limited. For instance, Darmal's (2009) study focuses on the experiences of six faculty members involved in the Department of Geography, and Noori et al.'s (2017) research included three lecturers who taught English as a Foreign Language. Since the government has introduced new regulations on assessment with a focus on types and number of questions in mid-term and final exams, exploring the experiences of students and faculty members can shed light on the meaningfulness of classroom assessment and create insight into the policy.

Although the existing literature provides mixed findings regarding the student perceptions of assessment based on gender, gender equity has been underscored as a key challenge in the higher education sector of 
Afghanistan (Babury \& Hayward, 2014; Mussawy \& Rossman, 2018). According to Babury and Hayward (2014), female students constitute less than $20 \%$ of the student population in universities. Since females are underrepresented in the higher education sector, examining students' perceptions of assessment based on gender will inform whether assessment practices serve male and female students evenly.

\section{Study Purpose}

The primary purpose of the study was to examine student perceptions of classroom assessment at a university in Afghanistan. Exploring current assessment practices focused on student and faculty lived experiences was a secondary purpose. The study also sought to collect evidence on whether the new Afghanistan assessment policy was effective in improving student learning. Cavanagh et al. (2005) suggested two strategies to understand the advantages and disadvantages of classroom assessment on student learning: (a) examining the research on assessment forms that teachers use; and (b) inquiring into students' perceptions of classroom assessment. This study used both strategies. More specifically, the research questions and hypotheses guiding the study are below.

1. What are the perceptions of students about classroom assessment? As part of this research question, gender and academic discipline differences were explored.

- Hypothesis 1: There is no significant difference in student perceptions of classroom assessment based on gender.

- Hypothesis 2: There is no significant difference in student perceptions of classroom assessment based on academic discipline.

2. What are the experiences of students and faculty members concerning classroom assessment?

\section{Significance of the Study}

This study contributes to the literature on classroom assessment. First, the study's findings provide new insights into how students perceive classroom assessment and whether the assessment outcomes affect their learning. Second, the research explored student and faculty lived experiences with classroom assessment. Specific attention was given to faculty pedagogical skills and assessment literacy. Third, teachers' challenges concerning the national assessment policy with a focus on grading practices are highlighted. The study also informs the conversation regarding student involvement in assessment processes and the challenges associated with the lack of student preparedness to pursue undergraduate degree programs.

\section{Theoretical Framework}

The study uses formative and summative assessment as an analytic lens to explore perceptions and experiences of classroom assessment among undergraduate students and faculty. Formative and summative assessment approaches are well explored in the literature (Scriven, 1967; Wiliam \& Black, 1996; Wiliam \& Thompson, 2008). Formative assessment in the United States refers to "assessments that are used to provide information on the likely performance of students on state-mandated test-a usage that might better be described as 'earlywarning summative"' (Wiliam \& Thompson, 2008, p. 60). Other places use formative assessment to provide feedback to students-informing them "which items they got correct and incorrect" (Wiliam \& Thompson, 2008, p. 60). Providing feedback to improve learning is a key component of formative assessment that benefits students in a higher education setting to achieve desirable outcomes (Black \& Wiliam, 1998; Nicole \& Macfarlane-Dick, 2006; Sadler, 1998). In other words, formative assessment allows instructors to help students engage in their own learning by exhibiting what they know and identifying their needs to move forward (Black \& 
Wiliam, 1998; Mansell et al., 2020; Wiliam, 2011). Formative assessment occurs in formal and informal forms such as quizzes, oral questioning, self-reflection, peer feedback, and think-aloud (Mansell et al., 2020; Wiggins \& McTighe, 2007). Formative assessment also influences the quality of teaching and learning while engaging students in self-directed learning (Stiggins \& Chappuis, 2005).

On the other hand, summative assessment is bound to administrative decisions (Wiliam, 2008). It occurs at the "end of a qualification, unit, module or learning target to evaluate the learning which has taken place towards the required outcomes" (Mansell et al., 2020, p. xxi). Summative assessment, known as assessment of learning, is primarily used "in deciding, collecting and making judgments about evidence relating to the goals of the learning being assessed" (Harlen, 2006, p. 103). Herrera et al. (2007, p. 13) argued that "assessment of achievement has become increasingly standardized, norm-referenced and institutionalized," which thus negatively affects the quality of teaching (Firestone \& Mayrowetz, 2000). For scholars like Stiggins and Chappuis (2005), student roles vary depending on assessment forms, suggesting that summative assessment enforces a passive role while formative assessment engages students in the process as active members.

While some studies promote formative assessment over summative assessment (Firestone \& Mayrowetz, 2000; Harlen, 2006), other studies emphasize the purpose and outcome of assessment activities with a focus on ways to utilize the information to improve the teaching and learning experience (Taras, 2008; Ussher \& Earl, 2010). Bloom (1969) also asserted that when assessment is aligned with the process of teaching and learning, it will have "a positive effect on student learning and motivation" (cited in Wiliam, 2008, p. 58). Assessment in general accounts for "supporting learning (formative), certifying the achievement or potential of individuals (summative), and evaluating the quality of educational institutions or programs (evaluative)" (Wiliam, 2008, p. 59). Black and Wiliam (2004) emphasized ways to use the outcomes of formative and summative assessment approaches to improve student learning. Taras (2008) argued that "all assessment begins with summative assessment (which is a judgment) and that formative assessment is, in fact, summative assessment plus feedback which the learner uses" (p. 466). According to Taras (2008), both formative and summative assessments require "making judgments," which might be implicit or explicit depending on the context (p. 468). In other words, Taras (2008) argued that assessment could not "be uniquely formative without the summative judgment having preceded it” (p. 468). Similarly, Wiggins and McTighe (2007) explained that formative assessment occurs during instruction rather than as a separate activity at the end of a class or unit. The literature on assessment underscores the importance of formative and summative assessment and ways that "assessment... feed into actions in the classroom in order to affect learning” (Wiliam \& Thompson, 2008, p. 63).

\section{Methods}

\section{Research Site}

The study was conducted at a public university in Northern Afghanistan. The university, established in 1993 and re-established in 2003, has seven colleges and 27 departments. The university has approximately 155 fulltime faculty members who serve approximately 5,000 students, $20 \%$ of whom are female. The facultystudent ratio at the university is $1 / 35$, and the staff-student ratio is $1: 70$. The university offers only undergraduate degrees.

\section{Procedure and Participants}

The authors used an explanatory sequential mixed-methods design to collect data from senior, junior, and some sophomore students. We administered the 24-item SPAQ to a random sample of 400 students from the Agriculture, Education, and Humanities colleges and received a response rate from 355 students (88.25\%). Following the administration of the SPAQ, the authors conducted document analysis (mainly policy documents on assessment) as well as semi-structured interviews with a purposeful sample of 25 individuals, 
seven faculty members, and 18 undergraduate students to explore their lived experiences concerning current assessment practices. The in-person interviews ranged from 30 to 70 minutes. The notation for this study can be written as QUAN $\rightarrow$ QUAL (Creswell \& Clark, 2017). The authors obtained approval of the Institutional Review Board prior to conducting the study.

\section{Instrument}

We adapted the SPAQ (Cavanagh et al., 2005) to examine students' perceptions of assessment. As a conceptual model, SPAQ assesses students' perceptions of assessment in the following five dimensions:

1. Congruence with planned learning (CPL)-Students affirm that assessment tasks align with the goals, objectives, and activities of the learning program;

2. [Assessment] Authenticity (AA)-Students affirm that assessment tasks feature real-life situations that are relevant to themselves as learners;

3. Student consultation (SC)-Students affirm that they are consulted and informed about the forms of assessment tasks being employed;

4. [Assessment] Transparency (AT) -The purposes and forms of assessment tasks are affirmed by the students as well-defined and are made clear; and

5. Accommodation to student diversity (ASD)-Students affirm they all have an equal chance of completing assessment tasks (Cavanagh et al., 2005, p. 3).

Since the original instrument was only used to measure science assessment, we adapted and translated it to correspond to other disciplines such as social science, agriculture, and humanities. The Dari/Farsi translation of SPAQ is located in Appendix A. Students' responses to the SPAQ were recorded on a 4-point Likert scale (4 $=$ Strongly Agree to $1=$ Strongly Disagree).

For the qualitative section of the study, we used a phenomenological approach to explore student and faculty experiences of classroom assessment (Rossman \& Rallis, 2016). Using a phenomenological approach in a qualitative study is important in "understanding meaning, for participants in the study, of the events, situations, and actions they are involved with, and of the accounts that they give of their lives and experiences" (Maxwell, 2012, p. 8). The authors used two semi-structured interview protocols (one for students and one for faculty) containing 19 open-ended questions to corroborate the results of the quantitative data. Appendices B and C contain the interview protocols for faculty and students, respectively. These protocols centered on four important themes of classroom assessment-methods, authenticity, transparency, and the use of assessment outcomes to improve learning-that emerged from the literature on perceptions of assessment.

Since the SPAQ and interview protocols were developed in English, one of the authors, fluent in English and Dari, used a forward translation approach to translate the instruments into Dari/Farsi. The English and Dari versions were shared with three experts who were fluent in both languages, and the translated versions were revised based on their comments and suggestions. Then, the instruments were pilot tested among senior and junior students and faculty members. The investigators conducted the survey and interviews once the research participants confirmed that the questionnaire and interview protocols were understandable in the local language. 


\section{Validity and Reliability}

Previous research confirmed the validity and reliability of SPAQ. For instance, Fisher et al. (2005) developed SPAQ and confirmed its validity by applying it to a sample consisting of 1,000 participants from 40 science classes in grades 8-10. Cavanagh et al. (2006) replicated the study and revised the instrument from 30 to 24 items. Dhindsa et al. (2007) administered the revised SPAQ with 1,028 Bruneian upper-secondary students. They reported Cronbach's alpha reliability (Cronbach, 1951) as "0.86" for 24 items, while it ranged from "0.64 to 0.77 " for subscales (p. 1269). Similarly, Koul et al. (2006) applied the original 30-item instrument and reported that Cronbach's alpha reliability coefficient for SPAQ subscales ranged from 0.63 to 0.83 . Lastly, Mussawy (2009) administered the revised SPAQ at Baghlan Higher Education Institution in Afghanistan and confirmed that the SPAQ was suitable for understanding student perceptions of assessment. Cronbach's alpha reliability coefficient in that study was 0.89 for all items (24), and it ranged from 0.61 to 0.76 for subscales. Thus, validity and reliability of SPAQ have been confirmed in secondary and tertiary education settings. The investigators used the triangulation technique to increase the study's validity by collecting data from different sources including the SPAQ, semi-structured interviews, and document analysis. Research methodologists, including Maxwell (2012) and Rossman and Rallis (2016), support that by using triangulation, researchers can reduce the risk of any chance combined with the data or covering only one aspect of the phenomenon that can result when using one particular method. Further, the Cronbach's alpha reliability coefficient was calculated to determine the extent to which items in each subscale measure the same dimension of students' perceptions of assessment.

\section{Analysis}

Descriptive analyses address the first research question about students' overall perceptions about assessment at the university. Two separate statistical analyses were performed to answer the research hypotheses testing whether there are statistical differences in student perceptions of assessment by academic discipline and gender. The investigators performed one-way, between-groups ANOVA to examine whether the difference between students' perceptions of assessment was statistically significant based on colleges/disciplines. Next, we conducted a $t$-test to analyze the difference in students' perceptions of assessment based on gender.

To analyze the qualitative data, initially, the interviews were transcribed and translated into English. Next, the authors organized the data, reviewed it for accuracy, and cross-checked the original translation to ensure the meanings were consistent (Marshall \& Rossman, 2016). Then, the authors applied accepted analysis practices such as "immersion in the data, generating case summaries and possible categories and themes, coding the data, offering interpretations through analytic memos, search for alternative understanding, and writing the report” to analyze the data inductively (Marshall \& Rossman, 2016, p. 217). We used NVivo 12 to code the data, run queries, and observe overlaps/connections among themes. The process, overall, was very interactive as the authors exchanged perspectives by writing analytic memos and reflections to draw connections between the qualitative themes and to corroborate the quantitative results (Marshall \& Rossman, 2016). In short, the qualitative analysis focused on the meaningfulness of classroom assessment based on lived experiences (Rossman \& Rallis, 2016).

\section{Results}

\section{Quantitative}

The Cronbach alpha reliability coefficient for all items in SPAQ was $\alpha=0.89$, suggesting strong internal consistency. Among the subcales within SPAQ, Transparency had the highest alpha reliability score of $\alpha=$ 0.75, and Congruence with Planned Learning had the lowest $\alpha=0.64$. The instrument reliability for subscales is consistent with previous research (see Dhindsa et al., 2007; Koul et al., 2006; Mussawy, 2009). Given 
that the alpha reliability results for the subscales of SPAQ were consistently above 0.63, according to Cortina (1993), the use of SPAQ was considered reliable (See Table 1).

The descriptive statistics show mean scores ranging from $M=2.99$ for the sub-scales Accommodation to Student Diversity to $M=3.30$ for Congruence with Planned Learning on a 4-point Likert scale (4 = strongly agree $-1=$ strongly disagree). The high mean scores suggest that students have a very positive perception of classroom assessment. Table 1 provides an illustration of sub-scales mean scores, standard deviations, and Cronbach alpha reliability.

Table 1. Sub-Scale Mean, Standard Deviation, and Cronbach Alpha Reliability Coefficient for the SPAQ and its Subscales

\begin{tabular}{lccc}
\hline SPAQ Scales & Mean & St. Dev & Alpha Reliability \\
\hline Congruence with planned learning & 3.30 & .506 & .644 \\
Assessment authenticity & 3.19 & .540 & .694 \\
Student consultation & 3.09 & .690 & .732 \\
Assessment transparency & 3.18 & .652 & .749 \\
Accommodation to student diversity & 2.99 & .710 & .698 \\
\hline Overall & 3.16 & .484 & .898 \\
\hline
\end{tabular}

The descriptive statistics associated with students' perceptions of classroom assessment across three colleges are reported in Table 2. The results show that participants from the College of Humanities were associated with the smallest mean value $(M=3.05, S D=.467)$; participants from the College of Education were associated with the highest mean value $(M=3.28, S D=.499)$; and participants from the College of Agriculture were in between $(M=3.19, S D=.397)$. A one-way, between-groups ANOVA was performed to test the hypothesis that college was associated with perceptions of classroom assessment. The assumption of homogeneity of variance was tested and satisfied based on Levene's test, $F(2,350)=.59, p=.55$.

Table 2. Average Scale-Item Mean, Average Item Standard Deviation, and Standard Error Results for College Level Differences in SPAQ Overall Scores

\begin{tabular}{|c|c|c|c|c|c|c|}
\hline \multirow[b]{2}{*}{ Colleges } & \multirow[b]{2}{*}{$N$} & \multirow[b]{2}{*}{$M$} & \multirow[b]{2}{*}{$S D$} & \multirow[b]{2}{*}{$\begin{array}{l}\text { Std. } \\
\text { Error }\end{array}$} & \multicolumn{2}{|c|}{$\begin{array}{l}\text { 95\% Confidence Interval for } \\
\text { Mean }\end{array}$} \\
\hline & & & & & $\begin{array}{l}\text { Lower } \\
\text { Bound }\end{array}$ & $\begin{array}{l}\text { Upper } \\
\text { Bound }\end{array}$ \\
\hline Education & 142 & 3.28 & .499 & .041 & 3.20 & $3 \cdot 37$ \\
\hline Humanities & 171 & 3.05 & .467 & .035 & 2.98 & 3.12 \\
\hline Agriculture & 40 & 3.19 & .397 & .062 & 3.06 & $3 \cdot 31$ \\
\hline Total & 353 & 3.16 & .484 & .025 & 3.11 & 3.21 \\
\hline
\end{tabular}

The independent between-groups ANOVA was statistically significant, $F(2,350)=9.45, p=.000, \eta^{2}=.058$. Thus, the null hypothesis of no difference between the mean scores was rejected, and $5.8 \%$ of variance was accounted for in the college group. To analyze the differences between the mean scores of the three colleges, we used Fisher's LSD post-hoc tests. The difference between students' perceptions from the College of Education and the College of Humanities was statistically significant across Congruence with Planned Learning, Assessment Authenticity, Student Consultation, and Accommodation to Student Diversity subscales. The difference between student perceptions from the Colleges of Education and Agriculture was 
only statistically significant for the Accommodations to Student Diversity subscale. Finally, the difference between students' perceptions of assessment from the Colleges of Agriculture and Humanities was not statistically significant across all scales. See Table 3 for further information on means and probability values.

Table 3. Average Scale-Item Mean, Average Item Standard Deviation, and ANOVA Results for College Differences in SPAQ Scale Scores

\begin{tabular}{lccccccccc}
\hline & Education & Humanities & Agriculture & \multicolumn{3}{c}{$\boldsymbol{p ~ v a l u e s}$} \\
\cline { 2 - 9 } Scale & $M$ & $S D$ & $M$ & $S D$ & $M$ & $S D$ & $\begin{array}{c}\text { Education } \\
\text { versus } \\
\text { Humanities }\end{array}$ & $\begin{array}{c}\text { Education } \\
\text { versus } \\
\text { Agriculture }\end{array}$ & $\begin{array}{c}\text { Agriculture } \\
\text { versus } \\
\text { Humanities }\end{array}$ \\
\hline CLP & 3.38 & .461 & 3.15 & .559 & 3.41 & .516 & .003 & .800 & .030 \\
AA & 3.26 & .602 & 3.04 & .540 & 3.20 & .571 & .005 & .494 & .260 \\
SC & 3.32 & .604 & 2.97 & .707 & 3.22 & .457 & .000 & .220 & .108 \\
AT & 3.25 & .686 & 3.11 & .639 & 3.19 & .558 & .059 & .816 & .325 \\
ASD & 3.21 & .621 & 2.85 & .706 & 2.94 & .572 & .000 & .009 & .467 \\
\hline
\end{tabular}

Lastly, an independent sample $t$-test was performed to determine if the mean scores between male $(N=258)$ and female $(N=95)$ students were statistically different. The assumption of homogeneity of variances was tested and satisfied via Levene's test, $F(351)=.551, p=.458$. The independent samples $t$-test was not associated with a statistically significant effect, $t(351)=-1.34, p=.17$. This suggests that the difference between students' perceptions of assessment based on gender was not statistically significant, and the null hypothesis was retained.

\section{Qualitative Section}

The qualitative results generated insights about important aspects of classroom assessment. Both students and faculty commented that the existing classroom assessment policies and practices favor exams, which center on summative assessment approaches. However, most faculty members reported that they implement both formative and summative assessment. Three themes emerged from the interviews with faculty and students: Improvement in pedagogy and assessment; student involvement in assessment processes; and assessment forms versus the grading policy. Findings suggest that awareness about different forms of assessment is high among the faculty. In addition, both students and faculty reported student involvement in assessment processes at some level. Further, all participants highlighted the restriction of the grading policy as an important challenge for faculty members to institutionalize alternative assessment approaches in addition to the existing high stakes assessment and for students to buy into assessment activities that are not tied to their grades. 


\section{Improvements in Pedagogy and Assessment Skills}

Most faculty indicated substantial growth in teaching and assessment competencies due to exposure to modern pedagogies provided at the national and institutional levels. A faculty member explained that universities in Afghanistan follow a cascade model of professional development for faculty. She added that the university has a team of experts facilitating training sessions on "outcome-based learning" and "studentcentered instruction." Another faculty member supported that the training sessions covered different assessment approaches. He explained, "I feel confident facilitating student-driven lessons and developing different assessment forms to assess my students." Similarly, a junior faculty reported that she had learned ways to create "individualized and collaborative assessment tasks." For these participants, professional development programs facilitated by the quality assurance office have increased their assessment literacy.

While the faculty participants noted improvements in their assessment skills, many students criticized them for failing to design assessment tasks that matched individual student capabilities. "My classmates come from different geographies where access to schools is limited. They have different learning abilities, but assignments and exams are the same for everyone," said a senior student from the College of Education. He added that not everyone has the same learning style, suggesting that faculty members should pay attention to the individualized needs of students. Nonetheless, students acknowledged assessment transparency and the recurrence of daily assessment during instruction. A senior student described that their "exams consist of simple, medium, and difficult questions." Nevertheless, a few students were skeptical about merit-based assessment, noting that final exams are sometimes politicized to promote one student group over another. While participants avoided providing specific details, the recent example flags assessment ethics centered on "fairness and equity" as teachers make judgments about student learning (Klenowski \& Wyatt-Smith, 2014, p. 7).

\section{Student Involvement in Assessment Processes}

Most of the faculty members who participated in the interviews expressed reluctance to involve the student in assessment tasks, particularly when grading a student's work. Nevertheless, they were open to the idea of having students review their peers' work and provide constructive feedback. One faculty member stated that he often encouraged students to make oral comments when their peers presented their projects, but he never asked them to provide written feedback. Other faculty members also recalled instances when they worked with students to solve a problem or discuss applying concepts and theories in practice. For these faculty, assessment and teaching are "inseparable." For instance, according to one faculty who was teaching writing courses, providing opportunities for students to ask questions and reflect on the lesson was central to her teaching philosophy. She went on to explain, "I usually provide lengthy feedback on students' papers by explaining the strengths, weaknesses, and ways to improve them.” The faculty member, nonetheless, acknowledged that she had never shared her assessment rubric with students.

Student engagement in assessment tasks only occurred in informal settings. Students explained that the faculty usually involve students in assessment when the subject requires them to conduct fieldwork and share their findings with the class. More precisely, a junior student said, "When we present the findings of our fieldwork, our classmates can ask questions or make comments about the presentation." He went on to say that a few faculty members had specific policies, for example, choosing referees among students to make judgments about student presentations. Another junior stated, "I felt much empowered when it was my turn to evaluate other students' presentations one day." He added, "I was a little nervous but so excited to serve as a referee." However, a few students complained about the purpose of peer assessment when there is no guideline from the instructor. According to a sophomore, "The faculty members should establish the grounding rules when they let students ask questions and assess the presentations. Some students ask difficult questions to challenge their classmates." While many of the students highlighted the importance of student involvement in assessment processes, the last example informs the role of faculty members in managing assessment. 
Given that classroom assessment occurs at different intervals, several faculty members complained about the lack of student preparedness for post-secondary education. They criticized secondary schools for failing to prepare students with adequate knowledge and skills to pursue undergraduate programs. For instance, a faculty member who facilitated a freshman course on academic writing described her experience: "Students barely know how to write. I had to revisit my course syllabus to meet their needs." For this participant and several other faculty members, improvements in classroom assessment partially address student-learning problems; they urged that the university consider supporting programs such as tutoring and peer mentoring.

\section{Assessment Forms and the Grading Policy}

Many students stated that they had experienced various forms of assessment activities. While midterm and final exams were the dominant forms of assessment, many faculty members integrated quizzes, assignments, and research projects in their syllabi. A senior student from the College of Education said, "Some faculty members assign us to complete individual or group projects. Once we complete the project, we present it in front of the class and respond to other students' questions." However, she highlighted that they do not often receive written evaluation [feedback] from most faculty members. The teaching load was too high for many faculty members to provide detailed feedback to student research. A student (junior) from the English Department emphasized creating portfolios as a form of assessment. She said, "Creating a portfolio is one of the requirements for our writing class. I follow the class schedule by adding a new piece of writing to my portfolio every other week. I feel very excited when I see progress in my writing over time." For these students, research projects were the dominant forms of assessment that occurred aside from exams.

Unlike the enthusiasm for formative assessment, students and faculty members expressed mixed experiences concerning high-stakes summative assessment. Students and faculty consistently objected to the grading policy for allocating $80 \%$ of grades for formal exams (mid-term and final) with only $20 \%$ for attendance, class participation, assignments, and other activities. According to a sophomore, "Our exams contain multiplechoice, true-false, matching, and open-ended questions." She added, "Class projects [research] that require much time reviewing different sources [literature] to collect information has only 10 points [10 percent of the grade]." Based on student responses, most faculty members give them 30 or more questions in exams.

Like students, several faculty members expressed dissatisfaction with the assessment policy, focusing on the grading policy. According to a faculty member from the College of Education, assessment guidelines only discuss assessment mechanics-such as the number and types of questions to be considered in an exam. Other faculty members also criticized the policy, stating that assessment guidelines are restricted to formal assessments such as mid-term and final exams. A faculty member who taught history referred to the policy implementation as policing the assessment process because the deans of colleges and senior leadership regularly supervised their exam sheets-making sure faculty followed the guidelines. The faculty participants also complained that the assessment guidelines had created new bureaucracies, requiring all faculty members to have their exams reviewed by the head of the department. "Faculty autonomy is just a rhetoric when we cannot control decisions on how to assess our students," said a junior faculty member.

Although dissatisfied with the grading policy, a few faculty members pointed out some improvements due to the policy change in the assessment. A senior faculty member from the College of Humanities explained, "Previously, we used to assess students by giving them 5-10 open-ended questions. The number of students failing the exams was also very high because each question valued approximately 10 percent of their grades." However, he added that the new assessment guidelines require the faculty to include various forms of questions in their exams to assess student learning. The last quote suggests a transition from a single form of question type, the open-ended essay questions, to the use of diverse questions in exams. 


\section{Discussion}

The study sought to provide insight on (a) student perceptions of classroom assessment, (b) whether a difference existed in student perceptions of assessment based on academic discipline and gender at the university, and (c) student and faculty experiences of assessment practices. The statistical results informing the first research question show that students have a very positive perception of assessment at the university. More precisely, the results suggest that according to students, assessment practices meet student expectations concerning learning abilities, learning outcomes, and relevance to real-life application. Student responses also confirm that faculty seek student input in developing assessment tools, and they have clarity about the aim and scope of assessment.

While there were no statistically significant differences in perceptions of male and female students, we found statistically significant differences for colleges/disciplines. In particular, the student perceptions from the College of Education and the College of Humanities were statistically different in SPAQ four subscalesCongruence with Planned Learning, Assessment Authenticity, Student Consultation, and Accommodation for Student Diversity. Furthermore, the difference in student perceptions from the College of Education and the College of Agriculture was only statistically different in one subscale-Accommodation for Student Diversity. At the same time, there were no statistically significant differences in student perception from the colleges of Agriculture and Humanities. The findings support the first null hypothesis - no significant differences exist in student perceptions of assessment based on gender-while rejecting the second null hypothesis that there are no differences in student perceptions of assessment based on academic discipline/college.

Our findings are consistent with previous research that students have positive perceptions of classroom assessment at the secondary and tertiary levels (Dhindsa et al., 2007; Koul et al., 2006; Mussawy, 2009; Waldrip et al. 2014). The study confirms Koul et al.'s (2006) and Mussawy's (2009) findings that no differences were noted in student perceptions based on gender. However, the results support differences in student perceptions of assessment based on academic discipline (Mussawy, 2009) and year in school (Grades 8-10) (Koul et al., 2006).

The findings informing the second research question show that a combination of formative and summative assessment practices is happening. More specifically, with faculty assessment literacy improved, students witnessed various assessment activities beyond the mid-term and final exams. At the same time, previous research identified poor assessment literacy and a tendency towards summative assessment as areas of concern among the faculty in Afghanistan (Mussawy, 2009; Noori et al., 2017). The findings of our study show substantial growth in faculty professional skills (i.e., teaching and assessment), which is consistent with previous research (Mussawy \& Rossman, 2021). However, students' lack of satisfaction with assessment politics and faculty's inflexibility to accommodate learners with different learning abilities contradict SPAQ sub-scales: Assessment Authenticity and Accommodations for Student Diversity results which were rated high The caveat in quantitative versus qualitative findings has methodological implications suggesting that student and faculty participants who complete surveys/questionnaires in Afghanistan tend to mark positive options. This implication is consistent with Hayward's (2017) study in which the faculty, who also served as peer-reviewers for accreditation in Afghanistan, were hesitant to mark any negative characteristics of another institution.

In addition, the study revealed that student involvement in assessment activities occurs at a surface level. This means that the faculty barely involves students in assessment activities that are bound to grades or entail written feedback. Peer assessment, however, widely occurs in student-led projects and presentations. Although student involvement seemed limited, the study findings support Falchikove's (2004) and Waldrip et al.'s (2014) argument suggesting that assessment tasks become more meaningful when students are involved in assessment development and/or application. Furthermore, the results offer some improvement to Mussawy's (2009) findings concerning faculty views and experiences of student engagement in peer and self- 
assessment. Ibarra-Sáiz et al. (2020) confirmed that involving students in assessment improves "their competence" and "evaluative judgment" (p. 151). Our study also reflects on Nicole and Macfarlane-Dick's (2006) conceptualization, suggesting that peer assessment not only "exposes students to alternative perspectives" but also motivates them to engage in learning more persistently (p. 211). Nevertheless, student concerns associated with lack of guidance, for example, related to rubrics used to provide feedback, were consistent with previous research (Mussawy, 2009; Noori et al., 2017).

The responses from students and faculty concerning the assessment forms suggest that a combination of formative and summative assessment is expected. Although the study results showed an increase in the number of students passing their courses, which supports the policy change, the dominance of summative assessment surfaced as an important challenge. In other words, the new assessment policy, according to the participants and policy documents, only addresses the number and type of questions in midterm and final exams but fails to deal with formative and summative assessment. More precisely, restrictions regarding the grading practices do not allow individual faculty to distribute grades into different activities that support student learning. Instead, the current arrangements force faculty to comply with the rules-allocating $80 \%$ of grades to high-stakes assessments. The distribution of grades, for many students, undermines the skills and knowledge gained through conducting individual and group projects. Therefore, student participants consistently complained that their individual/group projects are undervalued-leading to a superficial student engagement in individual and group projects. These findings confirm existing research on assessment in Afghanistan (Mussawy, 2009; Noori et al., 2017), that suggests that grading regulations delimit faculty members to evenly promote formative and summative assessment activities. In addition, improvement in student achievement, partly due to an increase in the number and type of questions at this university, supports Linn and Miller's (2005) argument that the likelihood of student success increases when there are more items in a test.

\section{Implications for Policy and Practice}

The study sought to examine student perceptions of assessment and collect evidence on the effectiveness of the new assessment policy in the higher education setting in Afghanistan. Results from this study suggest positive perceptions of assessment among students. While the policy change has contributed to student achievement to some extent, the restrictions on grading policy favor summative over formative assessment in practice. Revisions in the grading policy to ensure a balance between formative and summative evaluation are warranted. Given that students acknowledged formative assessment and student involvement, such as peer assessment, it is recommended that faculty consider developing guidelines and rubrics to serve as benchmarks for the formative assessment.

\section{Limitations and Future Research}

The SPAQ was initially developed to assess student perceptions in secondary schools in Australia and was replicated in other contexts, including Afghanistan. The study used a Dari/Farsi translation of SPAQ, which was adapted to match the higher education context at this university in Afghanistan. The study contributes to the scholarship by adapting and validating SPAQ to assess student perceptions of assessment in university settings. Further, the study paved the way for future research to examine student perceptions of assessment on a larger scale. The authors caution generalizations of the results because the sample represents only one public university. Similarly, the evidence on the effectiveness of the new assessment policy was based on perceptions and subjective views of faculty with some reference to previous studies. Future research should examine the relationship between student perceptions of assessment and how they engage in learning. Furthermore, participants of the study acknowledged some level of student involvement in assessment. Future studies may also focus on the meaningfulness of peer assessment among students and how assessment policies support or restrict peer assessment. 


\section{References}

Altbach, P. G. (2007). Tradition and transition: The international imperative in higher education. Sense Publisher. https://doi.org/10.1163/9789087903596

Babury, M. O., \& Hayward, F. M. (2013). A lifetime of trauma: Mental health challenges for higher education in a conflict environment in Afghanistan. Education Policy Analysis Archives, 21(68), 1-22. https://doi.org/10.14507/epaa.v21n68.2013

Babury, M. O., \& Hayward, F. M. (2014). Afghanistan higher education: The struggle for quality, merit, and transformation. Planning for Higher Education, 42(2), 1-32.

Beller, M., \& Gafni, N. (2000). Can item format (multiple choice vs. open-ended) account for gender differences in mathematics achievement? Sex roles, 42(1), 1-21. https://doi.org/10.1023/A:1007051109754

Bess, J. L. (1977). The motivation to teach. The Journal of Higher Education, 48(3), 243-258. https://doi.org/10.2307/1978679

Birenbaum, M., \& Feldman, R. (1998). Relationships between learning patterns and attitudes towards two assessment formats. Educational Research, 4O(1), 90-98.

https://doi.org/10.1080/0013188980400109

Black, P. J., \& Wiliam, D. (1998). Inside the black box: Raising standards through classroom assessment. King's College London School of Education.

Black, P. J., \& Wiliam, D. (2004). The formative purpose: Assessment must first promote learning. Yearbook of the National Society for the Study of Education, 103(2), 20-50. https://doi.org/10.1111/j.17447984.2004.tbooo47.x

Black, P., Harrison, C., \& Lee, C. (2003). Assessment for learning: Putting it into practice. McGraw-Hill Education.

Brown, S. (2005). Assessment for learning. Learning and teaching in higher education, (1), 81-89.

Cavanagh, R. F., Waldrip, B. G., Romanoski, J. T., Fisher, D. L., \& Dorman, J. P. (2005, December). Measuring student perceptions of classroom assessment. Paper presented at the annual meeting of the Australian Association for Research in Education, Parramatta, Australia.

Cortina, J. M. (1993). What is coefficient alpha? An examination of theory and applications. Journal of applied psychology, 78(1), 98-104. https://doi.org/10.1037/0021-9010.78.1.98

Creswell, J. W., \& Clark, V. L. P. (2017). Designing and conducting mixed methods research. Sage Publications.

Cronbach, L. J., \& Warrington, W. G. (1951). Time-limit tests: estimating their reliability and degree of speeding. Psychometrika, 16(2), 167-188. https://doi.org/10.1007/BFo2289113

Darmal, D. (2009). Assessment practice and perception of social science instructors in Afghanistan. Unpublished Master's capstone project, University of Massachusetts Amherst. Retrieved 12/12/2020.

Dhindsa, H., Omar, K., \& Waldrip, B. (2007). Upper Secondary Bruneian Science Students' Perceptions of Assessment. International Journal of Science Education, 29(10), 1281-1280. https://doi.org/10.1080/09500690600991149

Falchikov, N. (2004). Improving assessment through student involvement: Practical solutions for higher and further education teaching and learning. Routledge.

Firestone, W., \& Mayrowetz, D. (2000). Rethinking "high stakes:" Lessons from the US and England and Wales. Teachers College Record, 102(4), 724-749. https://doi.org/10.1111/0161-4681.00075 
Fisher, D. L., Waldrip, B. G., \& Dorman, J. P. (2005, April). Student perceptions of assessment: Development and validation of a questionnaire. Paper presented at the annual meeting of the American Educational Research Association, Montreal.

Goodrum, D., Rennie, L. J., \& Hackling, M. W. (2001). The status and quality of teaching and learning of science in Australian schools: A research report. Canberra: Department of Education, Training, and Youth Affairs.

Gulikers, J., Bastiaens, T., \& Kirschner, P. (2006). Authentic assessment, student and teacher perceptions: The practical value of the five-dimensional framework. Journal of Vocational Education and Training, 58(3), 337-357. https://doi.org/10.1080/13636820600955443

Harlen, W. (2006). On the relationship between assessment for formative and summative purposes. In J. Gardner (Ed.), Assessment and learning, (pp. 87-102). Sage Publications.

Hayward, F. M. (2017). Reflections on two decades of quality assurance and accreditation in developing economies. Planning for Higher Education, 46(1), 21-31.

Herrera, S.G., Murry, K. G., \& Cabral, R.M. (2007). Assessment accommodations for classroom teachers of culturally and linguistically diverse students. Pearson Education Inc.

Ibarra-Sáiz, M. S., Rodríguez-Gómez, G., \& Boud, D. (2020). Developing student competence through peer assessment: The role of feedback, self-regulation and evaluative judgement. Higher Education, 80, 137-156. https://doi.org/10.1007/s10734-019-00469-2

Klenowski, V., \& Wyatt-Smith, C. (2013). Assessment for education: Standards, judgement and moderation. Sage Publications.

Koul, R., Fisher, D., \& Earnest, J. (2006). Using student perceptions in the development, validation, and application of an assessment questionnaire. In Sharing wisdom for our future. Environmental education in action: Proceedings of the 2006 Conference of the Australian Association of Environmental Education (pp. 294-305).

Kwok, L. (2008). Students' perception of peer evaluation and teachers' role in seminar discussions. Electronic Journal of Foreign Language Teaching, 5(1), 84-97.

Linn, R. L., \& Miller, M.D. (2005). Measurement and assessment in teaching (9th ed.). Pearson Education, Inc.

Mansell, S., Gravells, A., \& Hampel, A. (2020). 50 assessment approaches: Simple, easy and effective ways to assess learners. Sage Publication.

Marshall, C. \& Rossman, G.B. (2016). Designing qualitative research. Sage Publications.

Maxwell, J. A. (2012). Qualitative research design: An interactive approach. Sage Publications.

Ministry of Higher Education. (2018). Assessment procedures and guidelines. Afghanistan: Ministry of Higher Education.

Mussawy, S. A. J. (2009). Assessment practices: Students' and teachers' perceptions of classroom assessment. Unpublished Master's Capstone Project, University of Massachusetts Amherst.

Mussawy, S. A. J., \& Rossman, G. B. (2018). Quality assurance and accreditation in Afghanistan: Faculty members' perceptions from selected universities. Higher Learning Research Communications, 8(2), 9-34. https://doi.org/10.18870/hlrc.v8i2.411

Mussawy, S.A.J., \& Rossman, G. B. (2021). Quality assurance and accreditation in Afghanistan: Exploring sensemaking and sensegiving in policy implementation, Quality in Higher Education, 27(1), 99-122. https://doi.org/10.1080/13538322.2020.1833419 
Nicol, D. J., \& Macfarlane-Dick, D. (2006). Formative assessment and self-regulated learning: A model and seven principles of good feedback practice. Studies in Higher Education, 31(2), 199-218. https://doi.org/10.1080/03075070600572090

Noori, A., Shafie, N. H., Mashwani, H. U., \& Tareen, H. (2017). Afghan EFL lecturers' assessment practices in the classroom. Imperial Journal of Interdisciplinary Research, 3(10), 130-143.

Ounis, T. (2017). Exploring secondary teachers' perceptions of classroom assessment in a Tunisian context. International Journal of Language and Linguistics, 4(2), 116-24.

Pellegrino, J. W., \& Goldman, S. R. (2008). Beyond rhetoric: Realities and complexities of integrating assessment into classroom teaching and learning. In C. A. Dwyer (Ed.). The future of assessment: Shaping teaching and learning. (pp. 53-82). Lawrence Erlbaum Associates.

Poskitt, J. (2014). Transforming professional learning and practice in assessment for learning. The Curriculum Journal, 25(4), 542-566. https://doi.org/10.1080/09585176.2014.981557

Rossman, G. B., \& Rallis, S. F. (2016). An introduction to qualitative research: Learning in the field. Sage Publications.

Sadler, D. R. (1998). Formative assessment: Revisiting the territory. Assessment in education: principles, policy \& practice, 5(1), 77-84. https://doi.org/10.1080/0969595980050104

Salmi, J. (2015). Is Big Brother watching you? The evolving role of the state in regulating and conducting quality Assurance. CIQG Publication Series. Council for Higher Education Accreditation.

Scriven, M. (1967). The methodology of evaluation. In R.W. Tyler, R.M. Gagne, \& M. Scriven (Eds.), Perspectives of curriculum evaluation (pp. 39-83). Rand McNally.

Segers, M., Nijhuis, J., \& Gijselaers, W. (2006). Redesigning a learning and assessment environment: The influence on students' perceptions of assessment demands and their learning strategies. Studies in Educational Evaluation, 32(3), 223-242. https://doi.org/10.1016/j.stueduc.2006.08.004

Stiggins, R., \& Chappuis, J. (2005). Using student-involved classroom assessment to close achievement gaps. Theory into practice, 44(1), 11-18. https://doi.org/10.1207/s15430421tip4401_3

Struyven, K., Dochy, F., \& Janssens, S. (2005). Students' perceptions about evaluation and assessment in higher education: A review. Assessment and Evaluation in Higher Education, 30(4), 325-341. https://doi.org/10.1080/02602930500099102

Taras, M. (2008). Summative and formative assessment: Perceptions and realities. Active Learning in Higher Education, 9(2), 172-192. https://doi.org/10.1177/1469787408091655

UNESCO-IIEP (International Institute for Educational Planning). (2004). Strategic action plan for the development of higher education in Afghanistan. Retrieved on 12/04/2020 from https://unesdoc.unesco.org/ark:/48223/pfooo0149508

Ussher, B. \& Earl, K. (2010). 'Summative' and 'formative': Confused by the assessment terms? New Zealand Journal of Teachers' Work, 7(1), 53-63.

Van de Watering, G., Gijbels, D., Dochy, F., \& Van der Rijt, J. (2008). Students' assessment preferences, perceptions of assessment and their relationships to study results. Higher Education, 56(6), 645658. https://doi.org/10.1007/s10734-008-9116-6

Waldrip, B. G., Fisher, D. L., \& Dorman, J. (2009). Identifying exemplary science teachers through their students' perceptions of the assessment process. Research in Science \& Technological Education, 27(1), 117-129. https://doi.org/10.1080/02635140802658958

Waldrip, B., Cox, P., Deed, C., Dorman, J., Edwards, D., Farrelly, C., Keeffe, M., Lovejoy, V., Mow, L., Prain, V. \& Sellings, P. (2014). Student perceptions of personalized learning: development and validation of a 
questionnaire with regional secondary students. Learning Environments Research, 17(3), 355-370. https://doi.org/10.1007/s10984-014-9163-0

Wiggins, G. P., \& McTighe, J. (2007). Schooling by design: Mission, action, and achievement. Association for Supervision and Curriculum Development.

Wiliam, D. (2008). Improving learning in science with formative assessment. In J. Coffey, R. Douglas, \& C. Stearns (Eds.), Assessing science learning: Perspectives from research and practice (pp. 3-20). NSTA Press.

Wiliam, D. (2011). What is assessment for learning? Studies in Educational Evaluation, 37(1), 3-14. https://doi.org/10.1016/j.stueduc.2011.03.001

Wiliam, D., \& Black, P. (1996). Meanings and consequences: A basis for distinguishing formative and summative functions of assessment. British Educational Research Journal, 22(5), 537-548. https://doi.org/10.1080/0141192960220502

Wiliam, D., \& Thompson, M. (2008). Integrating assessment with learning: What will it take to make it work? In C. A. Dwyer (Ed.). The future of assessment: Shaping teaching and learning. (pp. 53-82).

Lawrence Erlbaum Associates. https://doi.org/10.4324/9781315086545-3

The Higher Learning Research Communications (HLRC), is a peer-reviewed, online, interdisciplinary journal indexed in Scopus, ERIC, JGATE and Directory of Open Access Journals (DOAJ). It is an open access journal with an international focus published by Walden University, USA. Its aim is to disseminate both high quality research and teaching best practices in tertiary education across cultures and disciplines. HLRC connects the ways research and best practice contribute to the public good and impact the communities that educators serve. $H L R C$ articles include peer-reviewed research reports, research briefs, comprehensive literature reviews, and books reviews. 